Article

\title{
First-Principles Investigations of Single Metal Atoms (Sc, Ti, V, Cr, Mn, and Ni) Embedded in Hexagonal Boron Nitride Nanosheets for the Catalysis of CO Oxidation
}

\author{
Yi Liu ${ }^{1,2,3}$, Li-Ming Yang ${ }^{1,2,3, *}$ and Eric Ganz ${ }^{4}(\mathbb{D}$ \\ 1 Hubei Key Laboratory of Bioinorganic Chemistry and Materia Medica, School of Chemistry and Chemical \\ Engineering, Huazhong University of Science and Technology, Wuhan 430074, China \\ 2 Key Laboratory of Material Chemistry for Energy Conversion and Storage, Ministry of Education, School of \\ Chemistry and Chemical Engineering, Huazhong University of Science and Technology, \\ Wuhan 430074, China \\ 3 Hubei Key Laboratory of Materials Chemistry and Service Failure; School of Chemistry and Chemical \\ Engineering, Huazhong University of Science and Technology, Wuhan 430074, China \\ 4 School of Physics and Astronomy, University of Minnesota, 116 Church St. SE, Minneapolis, MN 55455, USA \\ * Correspondence: Lmyang.uio@gmail.com or Lmyang@hust.edu.cn
}

Received: 4 June 2019; Accepted: 6 July 2019; Published: 10 July 2019

\begin{abstract}
We evaluated isolated transition metal atoms ( $\mathrm{Sc}, \mathrm{Ti}, \mathrm{V}, \mathrm{Cr}, \mathrm{Mn}$, and $\mathrm{Ni}$ ) embedded in hexagonal-BN as novel single atom catalysts for $\mathrm{CO}$ oxidation. We predicted that embedded $\mathrm{Ni}$ atoms should have superior performance for this task. Ti, $\mathrm{V}$, and $\mathrm{Mn}$ bind $\mathrm{CO}_{2}$ too strongly and so the reaction will not proceed smoothly. We studied the detailed reaction processes for $\mathrm{Sc}, \mathrm{Cr}$, and $\mathrm{Ni}$. The Langmuir-Hinshelwood (LH), Eley-Rideal (ER), and the new termolecular Eley-Rideal (TER) processes for $\mathrm{CO}$ oxidation were investigated. Sc was not effective. Cr primarily used the ER process, although the barrier was relatively large at $1.30 \mathrm{eV}$. Ni was the best of the group, with a $0.44 \mathrm{eV}$ barrier for $\mathrm{LH}$, and a $0.47 \mathrm{eV}$ barrier for TER. Therefore, we predicted that the LH and TER processes could operate at relatively low temperatures between 300 and $500 \mathrm{~K}$.
\end{abstract}

Keywords: hexagonal boron nitride; single atom catalyst; $\mathrm{CO}$ oxidation; catalysis

\section{Introduction}

Catalytic converters play a crucial role in the reduction of toxic emissions from automobiles via the oxidation reaction of carbon monoxide (CO) [1]. This reaction has also become a prototype for the examination of the activity, selectivity, and durability of heterogeneous catalysts [2]. In recent decades, several groups have investigated and studied catalysts for $\mathrm{CO}$ oxidation. Noble metals including Pt [3-5], Rh [6,7], Pd [7,8], and Au [9-11] have been evaluated for the catalysis of CO oxidation. Noble metals are expensive and depletable resources. Therefore, it is important to find less expensive and more abundant alternatives. Over time, catalyst particle sizes have been substantially reduced. Potentially, one could reduce the size of the catalyst particles all the way to single atoms. Remarkably, these single atom metal catalysts show great potential to enhance catalytic activity and selectivity. [12,13].

There has been remarkable progress in experimental synthesis and the evaluation of single atom catalysts (SAC) [13-15]. Common synthetic methods include atomic layer deposition, wet chemistry, and soft-landing techniques. Preventing the aggregation of individual atoms into clusters is an important issue that has to be solved for each material. In 2011, Qiao et al. [13] were the first to 
prepare a practical Pt SAC supported by an iron oxide substrate $\left(\mathrm{Pt}_{1} / \mathrm{FeOx}\right)$. This had excellent catalytic performance, and it demonstrated that single atom catalysts could work experimentally. More recently, two-dimensional materials such as freestanding hexagonal boron nitride monolayers (h-BN) [16,17], graphene [18-20], graphyne [21,22], and $\mathrm{MoS}_{2}$ [23] have been proposed as substrates for single atom catalysts. These materials are predicted to have high catalytic activity for $\mathrm{CO}$ oxidation. These materials have high surface area and high thermal stability. Some experimental examples exist, such as individual Fe atoms mounted on graphene for the oxidation of benzene (which operates at $300 \mathrm{~K})$ [24], and individual Co atoms mounted on nitrogen doped graphene (to produce hydrogen) [25]. Our group proposed Mn embedded in graphene as a potential new SAC based on DFT calculations [26].

One can produce defects in h-BN nanosheets or nanotubes using controlled electron beam irradiation $[27,28]$. These defects consist of either boron or nitrogen vacancies (in this paper, we will focus on the B vacancy as described below). h-BN is normally a very inert and non-reactive material. The production of vacancies produces binding sites, which can capture individual metal atoms. These metal atoms can be strongly bound to the substrate, and they may also act as active catalysts under the right conditions. These metal-doped SACs may exhibit unique catalytic properties due to their unusual geometry and unsaturated metal sites. Recently, there have been numerous computational studies to design and evaluate h-BN SACs for the catalysis of CO oxidation [16,17,29-32]. For this purpose, Lin et al. have evaluated $\mathrm{Cu}, \mathrm{Ag}, \mathrm{Au}, \mathrm{Pt}, \mathrm{Rh}, \mathrm{Pd}, \mathrm{Fe}, \mathrm{Co}$, and Ir h-BN SACs [16]. They found that $\mathrm{Co}$ should be a good SAC for CO oxidation. Liu et al. studied Cu h-BN SACs [17]. Liu et al., Mao et al., Zhao et al., and Lu et al. studied Pt, Au, Fe, and Co h-BN SACs using DFT, respectively [29-32]. Lu et al. studied Ag h-BN in 2017 [33]. Sc, Ti, V, Cr, Mn, and Ni embedded in h-BN for CO oxidation have yet to be studied.

In this paper, we evaluated isolated $\mathrm{Sc}, \mathrm{Ti}, \mathrm{V}, \mathrm{Cr}, \mathrm{Mn}$, and $\mathrm{Ni}$ atoms located at defect sites in h-BN for use as single atom catalysts using density functional theory. We investigated the stability of these structures, and the catalytic activity for CO oxidation. We observed that Ni-h-BN is a promising SAC candidate.

\section{Results and Discussion}

\subsection{Geometry and Stability}

For the h-BN monolayer, there are two types of monovacancies: The B-vacancy and the $\mathrm{N}$-vacancy $[27,34]$. These involve the removal of a single $\mathrm{B}$ or $\mathrm{N}$ atom from the h-BN. We focused on the $\mathrm{M}-\mathrm{BN}$ materials with individual $\mathrm{Sc}, \mathrm{Ti}, \mathrm{V}, \mathrm{Cr}, \mathrm{Mn}$, or Ni metal atoms embedded into a vacancy. For metal atom catalytic sites located at the B-vacancy, (BM-BN), they were located at the center of the defect. The longest $\mathrm{Sc}-\mathrm{N}$ bond was $1.96 \AA$ whilst the shortest $\mathrm{Ni}-\mathrm{N}$ bond was $1.80 \AA$. Given the bond length, the Sc atoms were slightly up out of the h-BN plane. To evaluate the stability of these $\mathrm{M}-\mathrm{BN}$ materials, the binding energies of the metal atoms at the B-vacancy and at the $\mathrm{N}$-vacancy were calculated. For BM-BN, the binding energies were very strong and ranged from 8.4 to $12 \mathrm{eV}$ (see Figure 1). For the N-vacancy (NM-BN) materials, the binding energies were much weaker and ranged from 3.0 to $5.8 \mathrm{eV}$. This was consistent with previous experimental and theoretical work [27]. Owing to the high binding energy, for the rest of the paper, we investigated the B-vacancy BM-BN materials.

To evaluate the mobility of TM atoms on BM-BN, we calculated the diffusion barriers for the $\mathrm{Ni}$ atom as a representative example. We considered the atom moving from a defect site to a hollow site. Figure 2a shows the structures of the initial state (IS), transition state (TS), and final state (FS) for this process. Fermi level $\left(\mathrm{E}_{\mathrm{F}}\right)$ was set to zero.

We found a barrier of $5.5 \mathrm{eV}$ from IS to hollow site 1, and $6.3 \mathrm{eV}$ from IS to hollow site 2 . These barriers were larger than the 3.8 and $5.3 \mathrm{eV}$ barriers for the Pd-BN sheet [35]. Our results showed that, under normal conditions, Ni atoms would not diffuse significantly away from the B-vacancy sites, leading to good stability. 
To better understand the interaction between the $\mathrm{Ni}$ and B-vacancy, we performed an electronic structure analysis. We show the calculated Ni-3d and N-2p partial density of states in Figure $2 b$. We observed hybridization between these two states, due to the strong interaction between the $\mathrm{Ni}$ and the substrate.

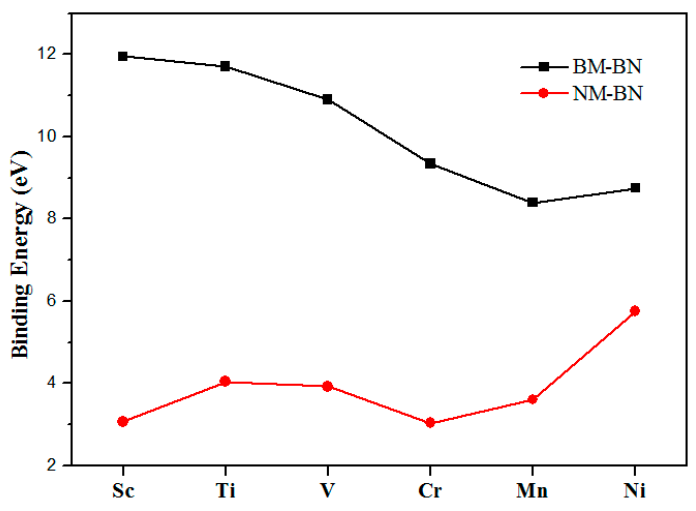

Figure 1. Binding Energy (in eV) for transition metal embedded h-BN with B-vacancy (BM-BN) or $\mathrm{N}$-vacancy (NM-BN).

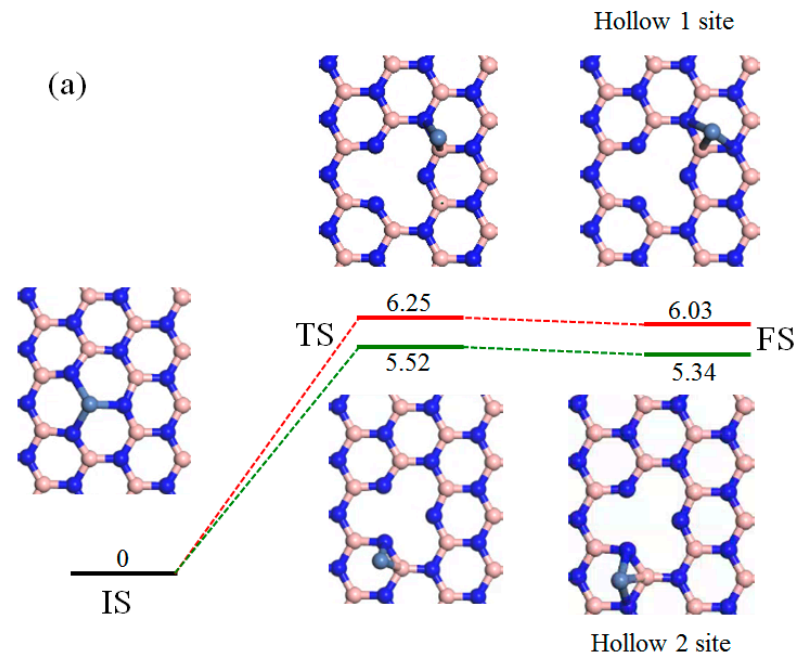

(a)

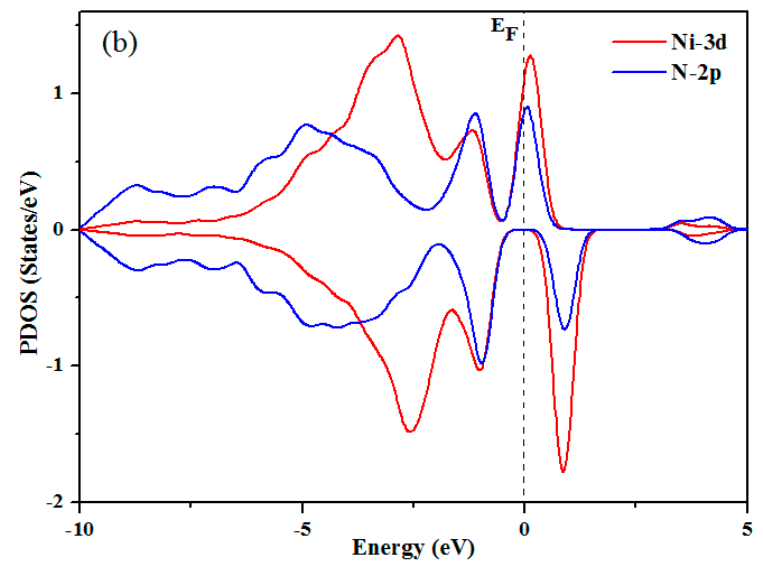

(b)

Figure 2. (a) Schematic energy levels for geometries for the diffusion of a single Ni atom for two different paths. Barriers of 6.3 and $5.5 \mathrm{eV}$ are observed. The initial state is labeled IS, the transition state is labeled TS, and the final state is labeled FS. (b) Partial density of states (PDOS) for the Ni-3d and N-2p states. 


\section{2. $\mathrm{O}_{2}, \mathrm{CO}, \mathrm{O}$, and $\mathrm{CO}_{2}$ Adsorption onto $\mathrm{Sc}, \mathrm{Cr}$, and Ni Atoms}

To further understand the $\mathrm{CO}$ oxidation process, the adsorption of $\mathrm{O}_{2}, \mathrm{CO}, \mathrm{O}$, and $\mathrm{CO}_{2}$ molecules on $\mathrm{Sc}, \mathrm{Cr}$, and $\mathrm{Ni}$ was investigated. $\mathrm{O}_{2}, \mathrm{CO}$, and $\mathrm{O}$ molecules had a strong interaction with these materials at the metal site. The calculated adsorption energies for the most stable structures are summarized in Table 1. These structures are shown in Figure 3.

Table 1. Optimized structures of adsorbed $\mathrm{CO}, \mathrm{O}_{2}, \mathrm{O}$, and $\mathrm{CO}_{2}$ molecules.

\begin{tabular}{cccccc}
\hline Substrate & Species & Adsorption Energy $(\mathbf{e V})$ & \multicolumn{2}{l}{ Bond Length $(\AA)$} & Mulliken Charge of Adsorbed Molecules $(|e|)$ \\
\hline \multirow{5}{*}{ Sc-BN } & $\mathrm{O}_{2}$ & 0.97 & $\mathrm{O}-\mathrm{O}$ & 1.33 & -0.43 \\
& $\mathrm{CO}$ & 0.63 & $\mathrm{C}-\mathrm{O}$ & 1.14 & 0.07 \\
& $\mathrm{O}$ & 6.62 & $\mathrm{Sc}-\mathrm{O}$ & 1.92 & -0.55 \\
& $\mathrm{CO}_{2}$ & 0.57 & $\mathrm{O}-\mathrm{C}-\mathrm{O}$ & $1.19,1.17$ & 0.03 \\
\hline \multirow{5}{*}{$\mathrm{Cr}-\mathrm{BN}$} & $\mathrm{O}_{2}$ & 2.47 & $\mathrm{O}-\mathrm{O}$ & 1.43 & -0.55 \\
& $\mathrm{CO}$ & 0.99 & $\mathrm{C}-\mathrm{O}$ & 1.16 & 0.05 \\
& $\mathrm{O}$ & 6.18 & $\mathrm{Cr}-\mathrm{O}$ & 1.60 & -0.53 \\
& $\mathrm{CO}_{2}$ & 0.36 & $\mathrm{O}-\mathrm{C}-\mathrm{O}$ & $1.19,1.17$ & 0.04 \\
\hline \multirow{5}{*}{$\mathrm{Ni}-\mathrm{BN}$} & $\mathrm{O}_{2}$ & 1.34 & $\mathrm{O}-\mathrm{O}$ & 1.33 & -0.27 \\
& $\mathrm{CO}$ & 1.23 & $\mathrm{C}-\mathrm{O}$ & 1.17 & 0.25 \\
& $\mathrm{O}$ & 3.79 & $\mathrm{Ni}-\mathrm{O}$ & 1.65 & -0.44 \\
& $\mathrm{CO}_{2}$ & 0.32 & $\mathrm{O}-\mathrm{C}-\mathrm{O}$ & $1.18,1.17$ & 0 \\
\hline
\end{tabular}

For $\mathrm{Ti}, \mathrm{V}$, and $\mathrm{Mn}$, the $\mathrm{CO}_{2}$ molecule would be strongly adsorbed, so these substrates may be poisoned and would not be good candidates for the catalysis of $\mathrm{CO}$ oxidation. For $\mathrm{Sc}, \mathrm{Cr}$, and $\mathrm{Ni}, \mathrm{CO}_{2}$ would be able to escape from the substrates, so these will be good candidates. The mixing between the Ni-3d and $\mathrm{CO}_{2}-2 \mathrm{p}$ states was low near $\mathrm{E}_{\mathrm{F}}$ (see Figure $3 \mathrm{~h}$ ), which was consistent with the weak interaction energy.

When a CO molecule is adsorbed onto the metal site, the most stable configuration has the $\mathrm{CO}$ adsorbed at a tilt (as shown in Figure 3a), with the carbon bonding to the $\mathrm{Sc}, \mathrm{Cr}$, or Ni sites. This result was very similar to the previous results on Co [32] and on Ag [33]-embedded h-BN. The calculated binding energies ranged from $0.63 \mathrm{eV}$ for $\mathrm{Sc}$ to $1.23 \mathrm{eV}$ for $\mathrm{Ni}$. For $\mathrm{CO}$ on $\mathrm{Ni}$, the $\mathrm{CO}$ bond lengths were $1.17 \AA$. These bond lengths were increased compared to the CO molecule by itself $(1.13 \AA) .0 .25|e|$ were transferred from the Ni to the $\mathrm{CO}$. Therefore, the $\mathrm{CO}$ had a small positive charge. Positively charged $\mathrm{CO}$ molecules on metal SACs were also predicted for $\mathrm{CO}$ on Al-graphene [21] and on $\mathrm{Co}-\mathrm{BN}$ [32]. On Sc and $\mathrm{Cr}$, the adsorbed $\mathrm{CO}$ was also positively charged. We now discuss the PDOS. This showed that the mixing between the Ni-3d and CO-2p orbitals was relatively weak near the Fermi level. Weak mixing was also observed for Ru-BN [36].

When $\mathrm{O}_{2}$ was adsorbed at the metal site, the best structure had two $\mathrm{M}-\mathrm{O}$ bonds that lay parallel to the M-BN support (as shown in Figure 3c). The adsorption energies ranged from 1.0 to $2.4 \mathrm{eV}(1.3 \mathrm{eV}$ for $\mathrm{Ni}$ ), which were larger than the corresponding $\mathrm{CO}$ absorption energies. The $\mathrm{O}-\mathrm{O}$ bond length increased from $1.23 \AA$ to $1.33 \AA$ (on Sc and $\mathrm{Ni}$ ) and $1.43 \AA$ (on $\mathrm{Cr}$ ), respectively. The $\mathrm{O}_{2}$ had a charge $-0.27|e|$. On $\mathrm{Sc}$ and $\mathrm{Cr}$, the adsorbed $\mathrm{O}_{2}$ was even more negatively charged. This suggested that these systems may have acted as electron donors for the electrophilic $\mathrm{O}_{2}$, which could help promote $\mathrm{O}_{2}$ activation. The hybridization between the Ni-3d and the $\mathrm{O}_{2}-2 \mathrm{p}$ states (see Figure $3 \mathrm{~d}$ ) was stronger than that for $\mathrm{CO}$ adsorption near $\mathrm{E}_{\mathrm{F}}$ (due to the higher binding energy). Therefore, $\mathrm{O}_{2}$ could be activated easily by the Ni SAC. A nearby CO molecule could then react with the $\mathrm{O}_{2}$ to ultimately produce $\mathrm{CO}_{2}$. This suggested that the Ni-BN SAC may be good for the catalysis of CO oxidation.

Next, we considered the adsorption of atomic $\mathrm{O}$ onto the $\mathrm{Sc}, \mathrm{Cr}$, and $\mathrm{Ni}$ metal sites. The optimized geometry is shown in Figure 3e. Atomic $\mathrm{O}$ had strong binding energies of 2.6, 6.2, and $3.8 \mathrm{eV}$ on $\mathrm{Sc}, \mathrm{Cr}$, and Ni. The length of the M-O bonds ranged from 1.6 to $1.9 \AA$. From Figure 3f, we observed that the $\mathrm{O}-2 \mathrm{p}$ states overlapped with the Ni-3d states. This reflected the strong hybridization in this case and indicated that atomic $\mathrm{O}$ would have high oxidation activity. 


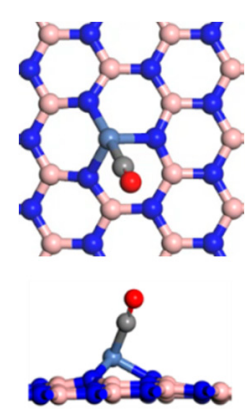

(a)

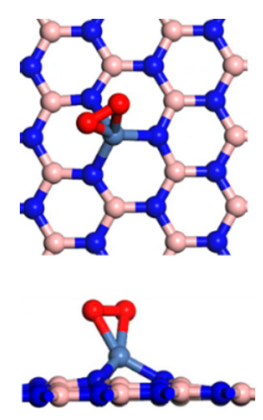

(c)
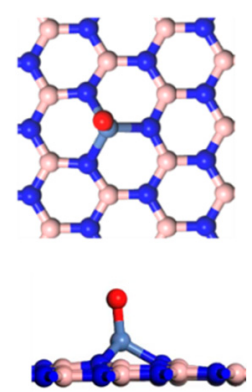

(e)

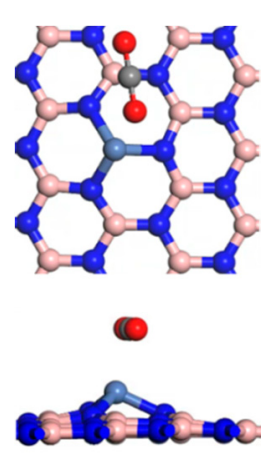

(g)

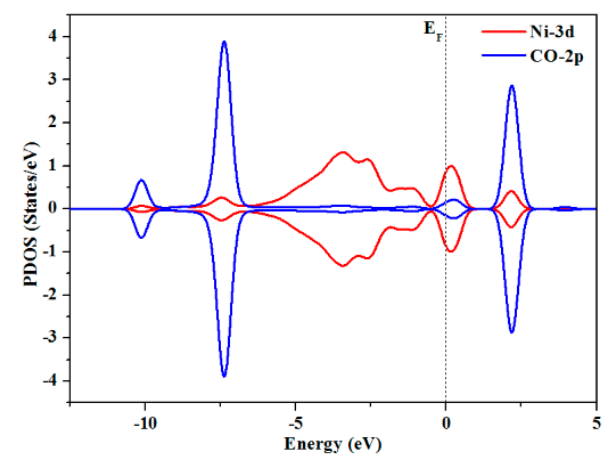

(b)

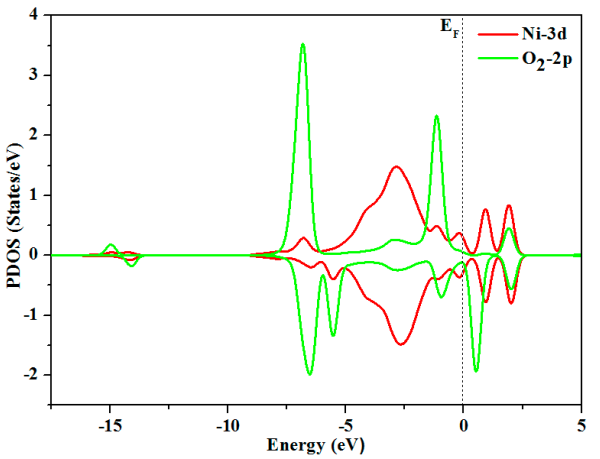

(d)

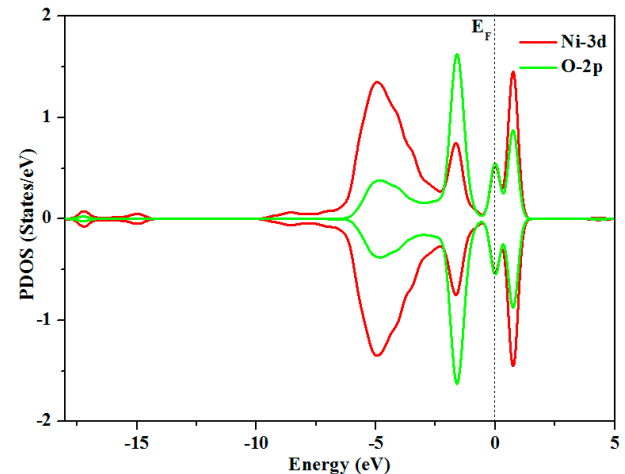

(f)

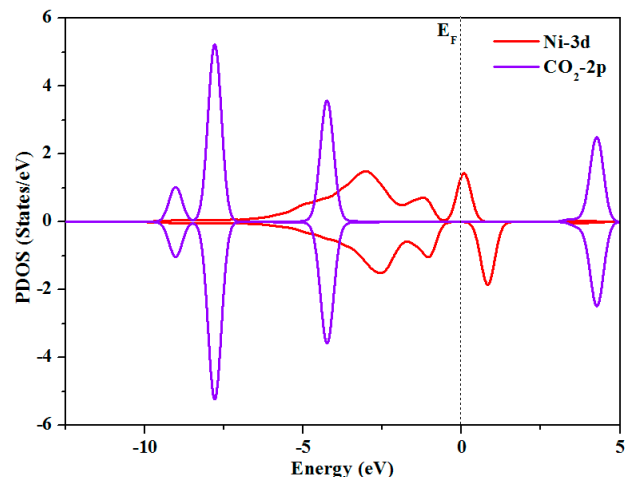

(h)

Figure 3. Optimized geometric structures and PDOS for the adsorbed $\mathrm{CO}(\mathbf{a}, \mathbf{b}), \mathrm{O}_{2}(\mathbf{c}, \mathbf{d}), \mathrm{O}(\mathbf{e}, \mathbf{f})$, and $\mathrm{CO}_{2}(\mathbf{g}, \mathbf{h})$. 
We show the frontier orbitals of $\mathrm{CO}, \mathrm{O}_{2}, \mathrm{O}$, and $\mathrm{CO}_{2}$ on $\mathrm{Ni}$ in Figure 4. The HOMO and LUMO are shown. For $\mathrm{CO}$, we observed significant hybridization between the $\mathrm{Ni}-3 \mathrm{~d}$ and the $\mathrm{CO}-2 \pi^{*}$ states of the $\mathrm{CO}$ in the HOMO-1 and HOMO-2. The Ni contribution to the HOMO was dominated by the $\mathrm{Ni}$ $\mathrm{d}_{\mathrm{p}}$ orbital. For $\mathrm{O}_{2}$, there was slight mixing between the $\mathrm{O}_{2}-2 \pi^{*}$ and the Ni-3d states in the HOMO. The $\mathrm{O}-2 \mathrm{p}$ and Ni-3d also overlapped. These results clarified the detailed molecular orbital interactions for $\mathrm{CO}, \mathrm{O}_{2}$, and $\mathrm{O}$ on $\mathrm{Ni}-\mathrm{BN}$. In contrast, there was virtually no orbital interaction between $\mathrm{CO}_{2}$ and Ni-BN. This was consistent with the fact that $\mathrm{CO}_{2}$ had very low interaction energy with Ni-BN. Therefore, $\mathrm{CO}_{2}$ could easily escape from the substrate.

The adsorption energies of the reactants on the substrates suggested a competition between $\mathrm{CO}$ and $\mathrm{O}_{2}$ adsorption at the $\mathrm{Sc}$ and Ni. For $\mathrm{Cr}-\mathrm{BN}, \mathrm{O}_{2}$ was likely to be adsorbed on the $\mathrm{Cr}$ atom sites, which allowed reactions with additional $\mathrm{CO}$ molecules from additional Eley-Rideal (ER) steps. For Ni-BN, the strength of the $\mathrm{CO}$ and $\mathrm{O}_{2}$ adsorption was similar. Therefore, several processes were investigated below.

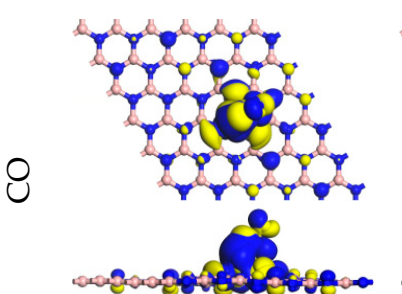

HOMO-2
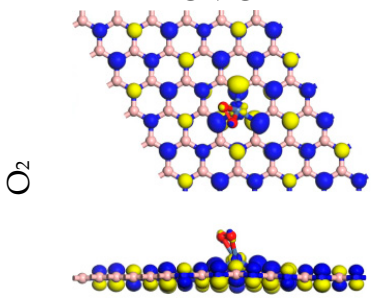

HOMO-2
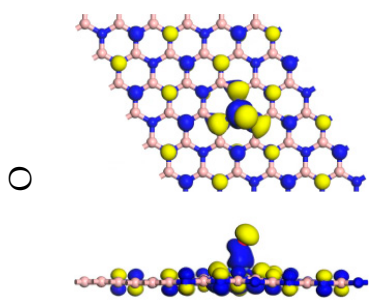

HOMO-2

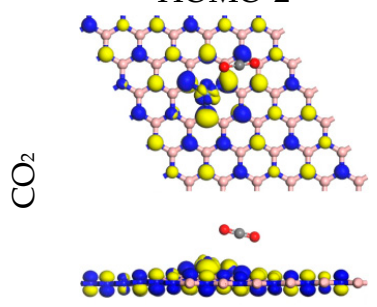

HOMO-2
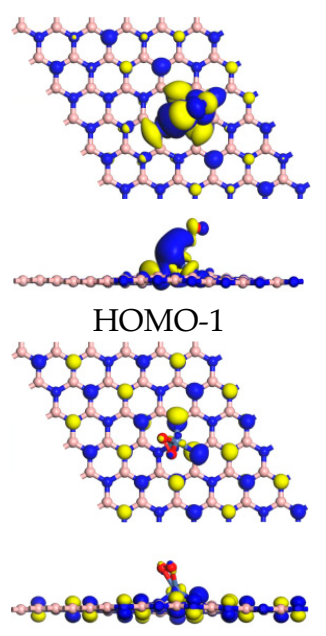

HOMO-1
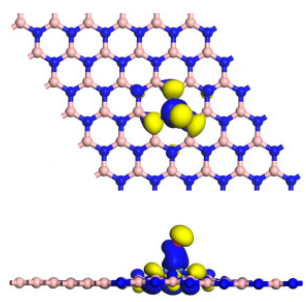

HOMO-1
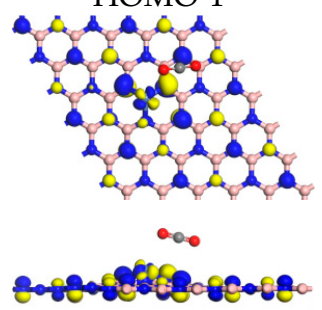

HOMO-1
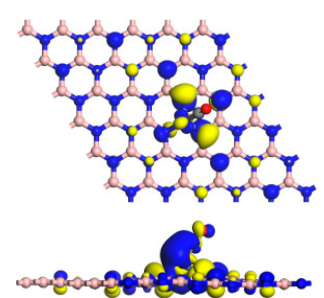

$\mathrm{HOMO}$
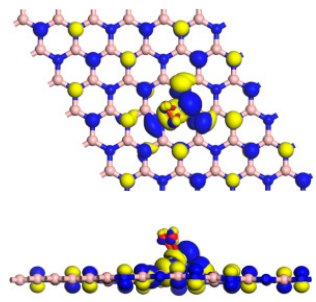

$\mathrm{HOMO}$
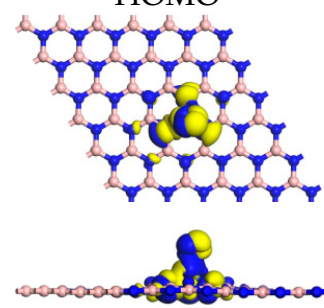

$\mathrm{HOMO}$
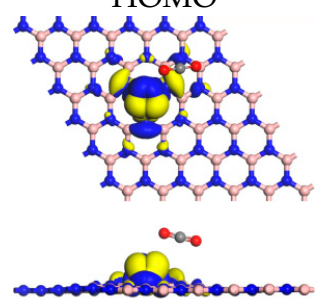

$\mathrm{HOMO}$
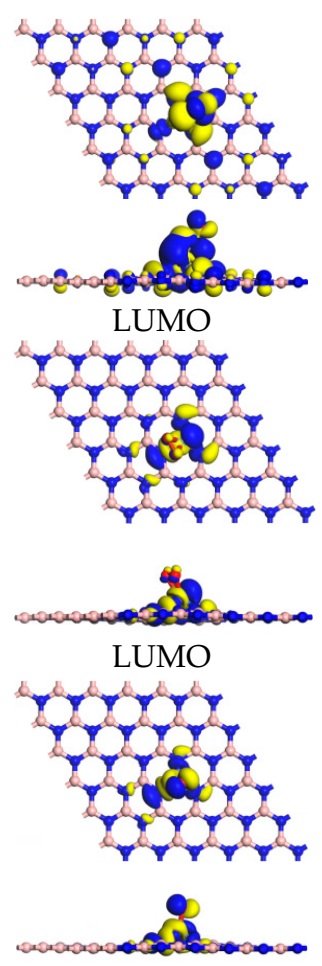

LUMO

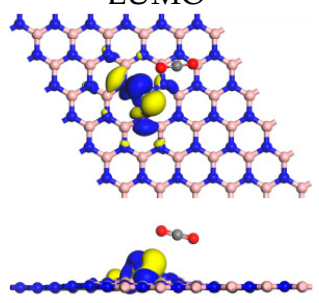

LUMO

Figure 4. The frontier highest occupied molecular orbitals HOMO-2, HOMO-1, HOMO, and lowest unoccupied molecular orbitals ( $\mathrm{LUMO}$ ) for $\mathrm{CO}, \mathrm{O}_{2}, \mathrm{O}$, and $\mathrm{CO}_{2}$ on $\mathrm{Ni}$ at the $\Gamma$-point. $\mathrm{B}$ atoms are beige, $\mathrm{N}$ atoms are blue, $\mathrm{C}$ atoms are gray, $\mathrm{O}$ atoms are red. The molecular orbitals are plotted in blue and yellow. The adsorbed molecules are located slightly above the plane.

\subsection{Reaction Mechanism of CO Oxidation}

The reaction process for single atom catalysts often includes a series of adsorption and desorption steps. The reaction barriers determine the catalytic efficiency. The traditional mechanisms of CO oxidation 
include the Eley-Rideal (ER) and the Langmuir-Hinshelwood (LH) processes [32,35]. In the ER scheme, a preadsorbed $\mathrm{O}_{2}$ molecule is activated by the support (in our case, $\mathrm{M}-\mathrm{BN}$, see Figure 5a). In the first stage, the $\mathrm{O}_{2}$ interacts with a free gas-phase $\mathrm{CO}$ to form a bound $\mathrm{CO}_{3}$ intermediate state. The result of the first stage is a single free $\mathrm{CO}_{2}$ product, and a remaining single atomic $\mathrm{O}$ bound to the catalyst. The catalyst facilitates the dissociation of the $\mathrm{O}_{2}$ at the catalyst site. In the second stage (see Figure $5 b$ ), the remaining adsorbed atomic $\mathrm{O}$ reacts with another free $\mathrm{CO}$ to create another $\mathrm{CO}_{2}$ product (which desorbs).
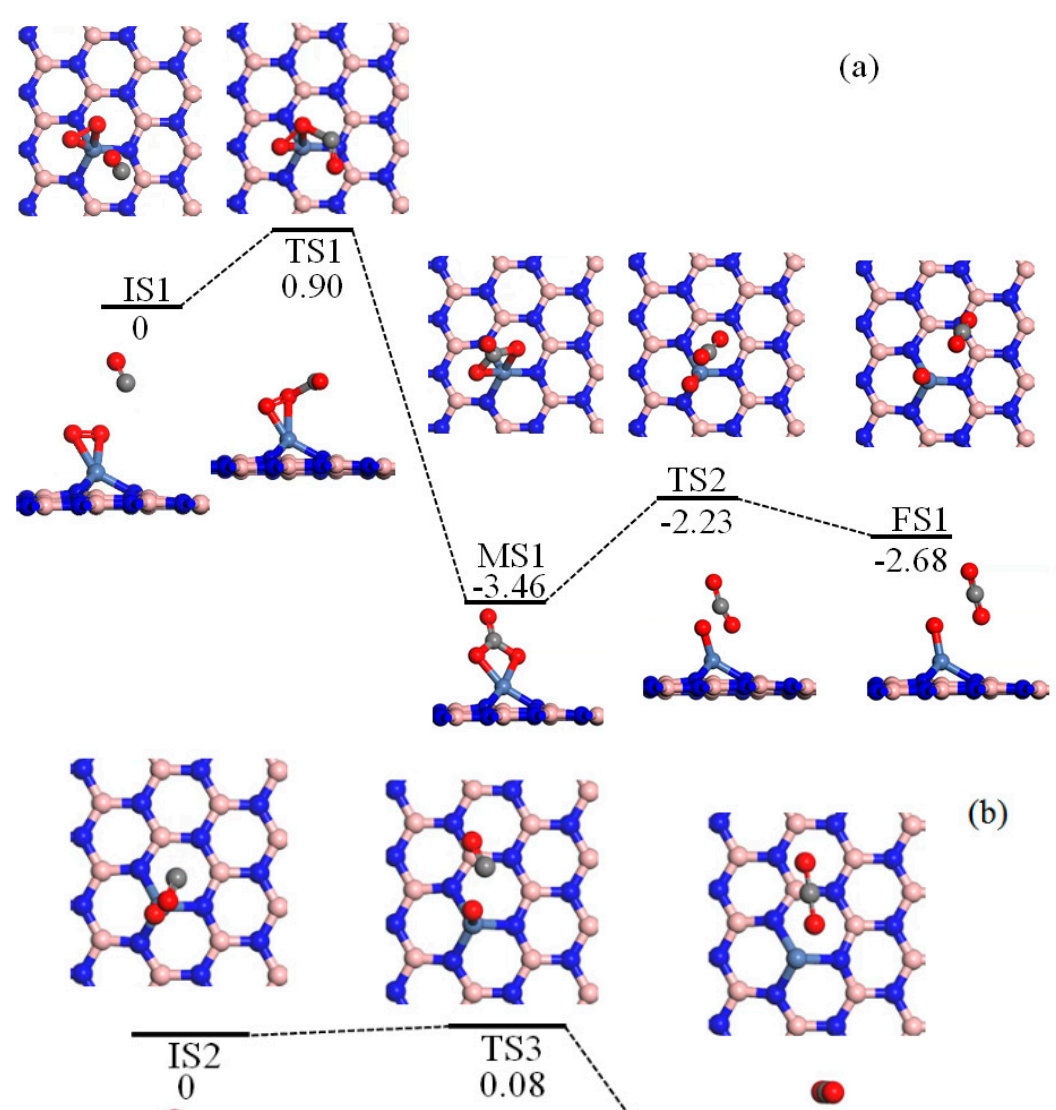

(b)
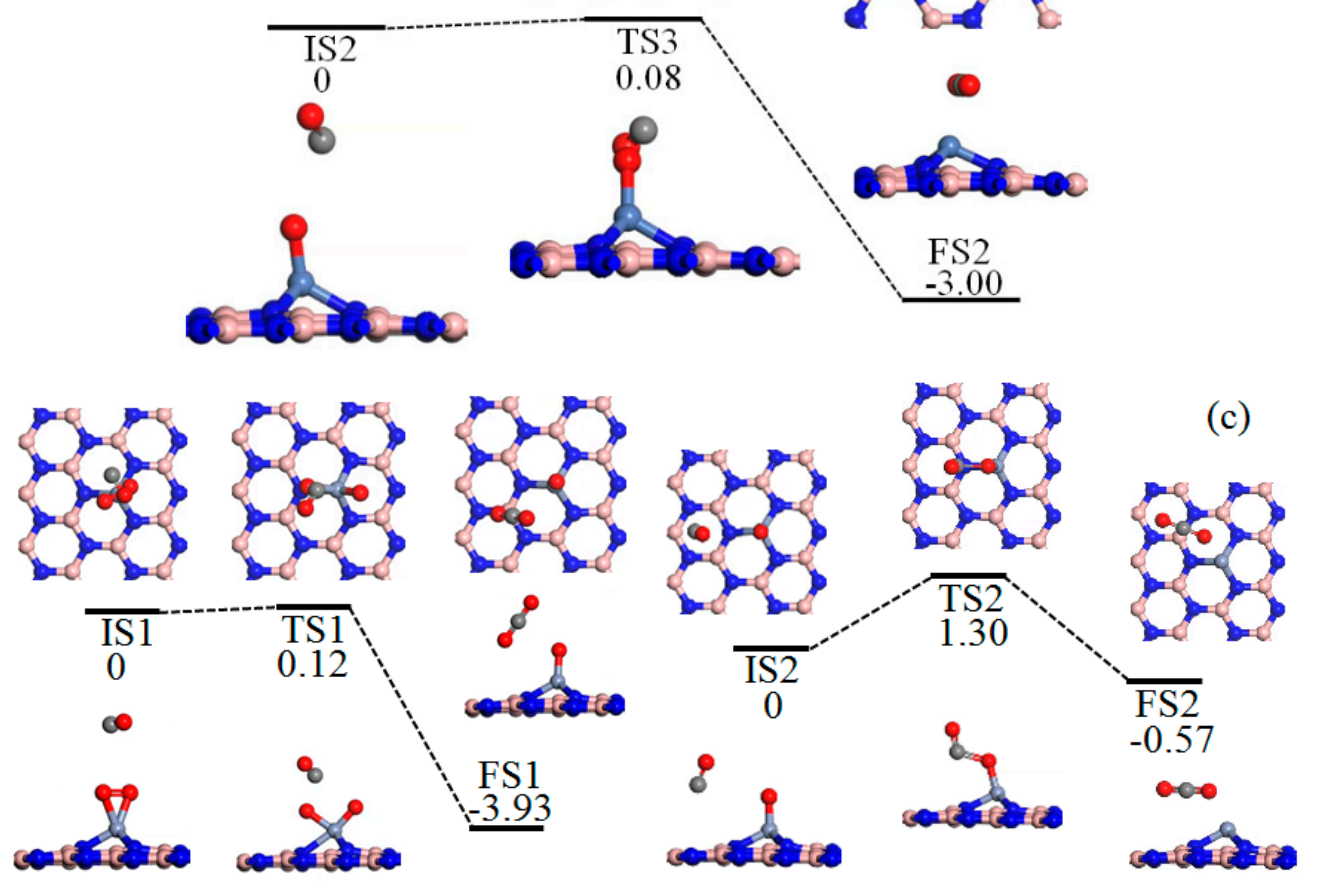

Figure 5. Reaction energies with associated geometries for CO oxidation via the Eley-Rideal (ER) process for (a) Ni-BN first stage, (b) Ni-BN second stage, and (c) $\mathrm{Cr}-\mathrm{BN}$ both stages. 
The $\mathrm{LH}$ process begins with the co-adsorption of $\mathrm{O}_{2}$ and $\mathrm{CO}$ molecules on the support. This is followed by the creation of an $\mathrm{O}-\mathrm{C}-\mathrm{O}-\mathrm{O}$ intermediate state, which is peroxide-like (see Figure 6). In the first stage, a $\mathrm{CO}_{2}$ molecule is desorbed. In the 2nd stage, atomic $\mathrm{O}$ interacts with a $\mathrm{CO}$ molecule to create a second $\mathrm{CO}_{2}$ which is desorbed.

A new, more complicated $\mathrm{CO}$ oxidation process has recently been found. Yang et al. have described this termolecular Eley-Rideal process [30]. In this case, we started with two molecules located on the substrate. In our case, two $\mathrm{CO}$ were located on the Ni-BN substrate (see Figure 7). A free $\mathrm{O}_{2}$ was activated and reacted with the two adsorbed molecules to create an intermediate state OCO-Ni-OCO. This state could then lead to the release of two $\mathrm{CO}_{2}$ molecules.

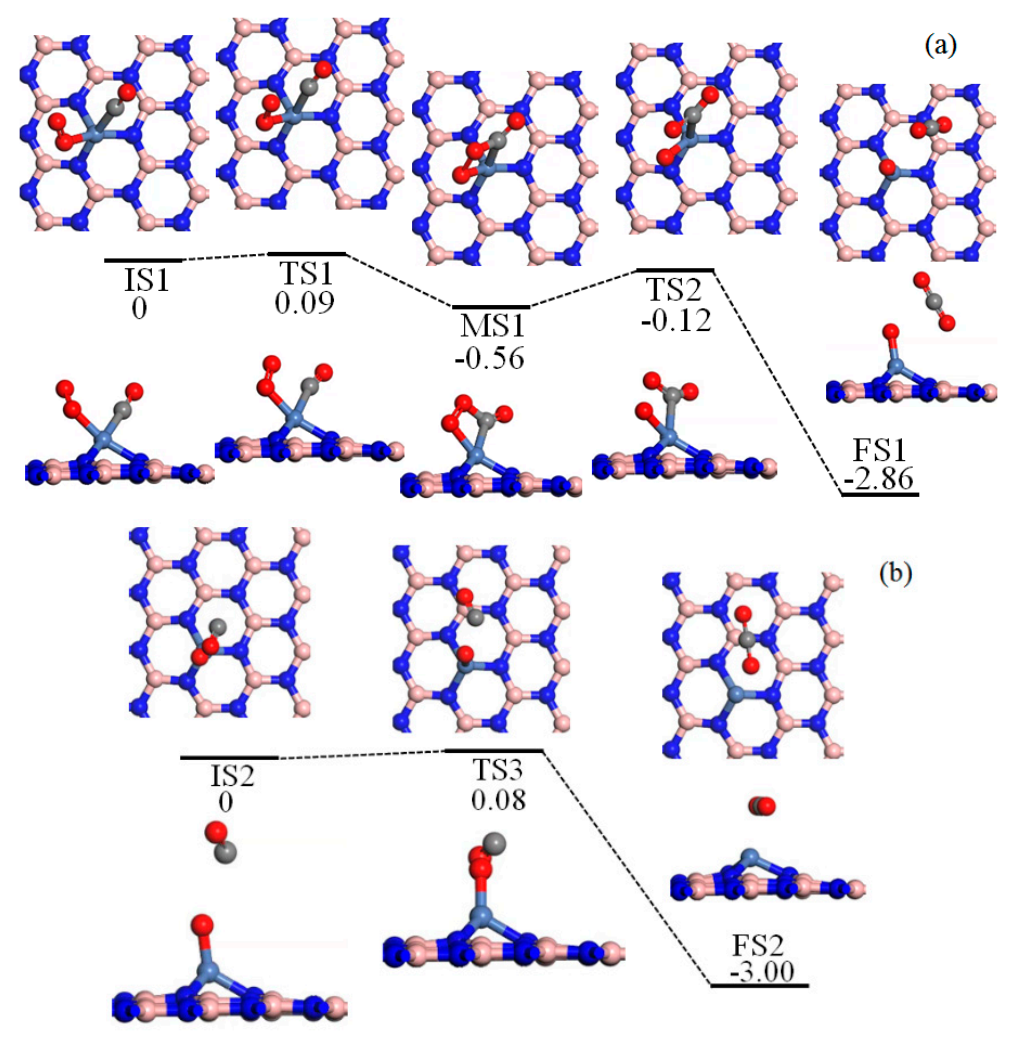

Figure 6. Reaction energies with associated geometries in the $\mathrm{LH}$ process for $\mathrm{CO}$ oxidation on $\mathrm{Ni}$. $\mathrm{O}_{2}$ and $\mathrm{CO}$ are co-adsorbed on the support, and have come together to form a peroxide like intermediate IS1. (a) First stage of LH process. (b) Second stage of LH process.

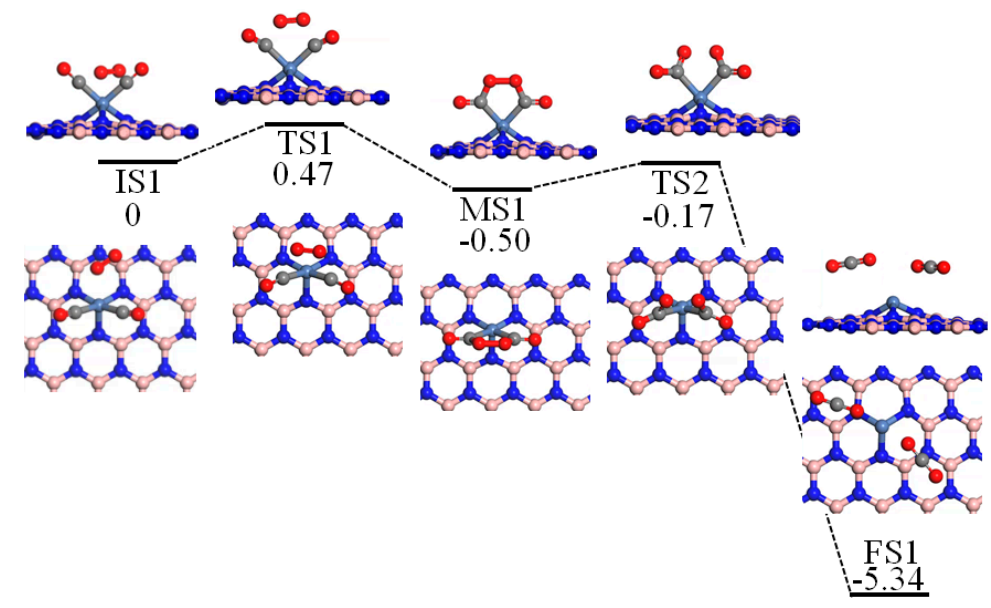

Figure 7. Reaction energies for the Termolecular Eley-Rideal (TER) process of CO oxidation on Ni-BN. 


\subsection{ER Process}

We first discuss the Eley-Rideal pathway to oxidize CO on Ni-BN. We present the potential-energy diagram and the geometries of the initial state, intermediate states, transition states, and products in Figure 5. We started with the $\mathrm{O}_{2}$ adsorbed on the Ni catalyst site. Moreover, the $\mathrm{CO}$ was located relatively close to the $\mathrm{O}_{2}$, but not significantly interacting. This was the initial state (IS1). When the CO approached the bound $\mathrm{O}_{2}$, the $\mathrm{O}_{2}$ bond could break to form two new $\mathrm{C}-\mathrm{O}$ bonds, and an intermediate state (MS1) was formed. This step had a $0.9 \mathrm{eV}$ barrier, with $3.5 \mathrm{eV}$ net exothermic energy. Then, the carbonate-like intermediate state (MS1) could dissociate into a free molecule of $\mathrm{CO}_{2}$ and an $\mathrm{O}$ atom bound to the Ni. This involved breaking one C-O bond, with barrier $1.2 \mathrm{eV}$, and $0.8 \mathrm{eV}$ net endothermic reaction energy $\left(\mathrm{E}_{\text {reaction }}\right)$. At room temperature, the newly created $\mathrm{CO}_{2}$ could be released as product. The $\mathrm{E}_{\text {ads }}$ value of $\mathrm{CO}_{2}$ was $0.26 \mathrm{eV}$ in the FS1 structure, very low. Owing to the rather weak adsorption energy, and the long distance to the substrate, the $\mathrm{CO}_{2}$ product could be easily released. In the second stage, another $\mathrm{CO}$ molecule could approach and react with the bound $\mathrm{O}$ (IS2 in Figure 5b) to form a second $\mathrm{CO}_{2}$ molecule. This second molecule could also escape as product. This step had a small $0.08 \mathrm{eV}$ barrier, and exothermic $\mathrm{E}_{\text {reaction }}=3.0 \mathrm{eV}$. The rate-limiting step of this ER process was in stage 1 in the creation of $\mathrm{CO}_{2}$ from the intermediate state and had barrier $1.2 \mathrm{eV}$, which was relatively large.

In Figure $5 c$, we show the geometries and energies for the intermediate states for the ER oxidation of $\mathrm{CO}$ on $\mathrm{Cr}$. The initial state was $\mathrm{O}_{2}$ adsorbed on the $\mathrm{Cr}$ site. One $\mathrm{CO}$ molecule reacted with the $\mathrm{O}_{2}$, causing the $\mathrm{O}-\mathrm{O}$ bond to break in the transition state (TS1). Then, a $\mathrm{CO}_{2}$ molecule could form with a small $0.1 \mathrm{eV}$ barrier, and a large exothermic $\mathrm{E}_{\text {reaction }}=3.9 \mathrm{eV}$. Subsequently, a second $\mathrm{CO}$ could interact with the remaining bound oxygen (IS2) to create another $\mathrm{CO}_{2}$ molecule which could desorb. This step had a large $1.3 \mathrm{eV}$ reaction barrier (TS2). Considering the alternative case of Sc, the intermediate states of $\mathrm{CO}$ and $\mathrm{O}_{2}$ could not easily dissociate into free $\mathrm{CO}_{2}$ molecules, so the ER process could not be active in this case.

\subsection{LH Process}

The reaction pathway of $\mathrm{CO}$ oxidation via the LH process is displayed in Figure 6. In this case, the $\mathrm{CO}$ and $\mathrm{O}_{2}$ co-adsorbed onto the metal atom. These could then react to form a peroxide-like intermediate. This state was selected as the initial state (IS1). Then, one oxygen atom of the $\mathrm{O}_{2}$ molecule approached the CO molecule to form the intermediate state MS1. This step had a $0.09 \mathrm{eV}$ reaction barrier, and an exothermic $\mathrm{E}_{\text {reaction }}=0.56 \mathrm{eV}$. This state was peroxide-like. MS1 could continue forward to create one $\mathrm{O}$ on the surface and one $\mathrm{CO}_{2}$ into the gas phase with a reaction barrier of $0.44 \mathrm{eV}$. One $\mathrm{O}$ was left on the Ni site with a Ni-O bond of $1.65 \AA$. This $\mathrm{O}$ could then join a CO molecule to create a second free $\mathrm{CO}_{2}$. For the entire process, a $0.44 \mathrm{eV}$ barrier was found for the rate limiting step $\mathrm{OOCO}(\mathrm{ad}) \rightarrow \mathrm{CO}_{2}$ (gas) $+\mathrm{O}(\mathrm{ad})$. As a result of the weak binding between the $\mathrm{CO}_{2}$ and the catalytic site, product $\mathrm{CO}_{2}$ molecules could be spontaneously released. This formed a complete cycle and then the system was ready for another round of catalysis. Note that $\mathrm{CO}$ and $\mathrm{O}_{2}$ cannot easily be co-adsorbed on $\mathrm{Cr}$ and Sc, so the LH process will not be active for these metals. This low reaction barrier would allow rapid catalytic activity due to the significant exothermic $\mathrm{E}_{\text {reaction }}=2.30 \mathrm{eV}$.

\subsection{TER Process}

A new three-molecule process was recently reported for single Au catalytic sites in h-BN [30]. After that, the TER process for CO oxidation was also found to occur on single Co [32] and Pd [35] catalytic sites in h-BN. Reaction energies for the TER process for Ni are shown in Figure 7. The first step involves two $\mathrm{CO}$ molecules bound to a catalytic $\mathrm{Ni}$ site. Then, a free $\mathrm{O}_{2}$ approaches the two co-adsorbed CO molecules, which creates an OCO-Ni-OCO state (MS state in Figure 7). This step had a $0.47 \mathrm{eV}$ reaction barrier, with an exothermic $\mathrm{E}_{\text {reaction }}=0.50 \mathrm{eV}$. This state also had an unusual pentagonal structure. In this state, we observed an increase in the O-O bond length to $1.50 \AA$. In the next step, the $\mathrm{O}-\mathrm{O}$ bond would be broken and two $\mathrm{CO}_{2}$ molecules were created on the surface. These two $\mathrm{CO}_{2}$ molecules only had a $0.32 \mathrm{eV}$ binding energy, and so they could move into the gas phase. This step 
had a large exothermic $\mathrm{E}_{\text {reaction }}=5.30 \mathrm{eV}$. This formed a complete cycle. This process was $2 \mathrm{CO}(\mathrm{ad})+$ $\mathrm{O}_{2} \rightarrow \mathrm{OCO}-\mathrm{Ni}-\mathrm{OCO}(\mathrm{ad}) \rightarrow 2 \mathrm{CO}_{2}$ (gas). The conversion of $\mathrm{O}_{2}$ to OCO-Ni-OCO dominated the reaction rate, and this had a barrier of $0.47 \mathrm{eV}$. We note that in the first step, the adsorbed $\mathrm{CO}$ had a positive charge. This may help promote $\mathrm{O}_{2}$ activation [30]. Two CO molecules are not typically co-adsorbed on Sc-BN under normal conditions, so the TER process will not be active for Sc.

In summary, the energy barrier of the rate-limiting step for the LH process was dramatically lower than that for the ER process $(0.44 \mathrm{eV}$ vs. $1.23 \mathrm{eV})$ and just a little lower than that for the TER process ( 0.44 vs. $0.47 \mathrm{eV}$ ). Therefore, the $\mathrm{LH}$ process and the TER process (CO-promoted $\mathrm{O}_{2}$ activation) were predicted to be dominant. The difference between the adsorption energy of $\mathrm{CO}(1.23 \mathrm{eV})$ and that of $\mathrm{O}_{2}(1.34 \mathrm{eV})$ may not be significant. Preadsorption or exposure to $\mathrm{CO}$ or $\mathrm{O}_{2}$ could determine the concentration of $\mathrm{CO}$ and $\mathrm{O}_{2}$ on the surface.

\subsection{Effect of Temperature and Entropy}

We considered the effects of temperature and entropy on the reaction thermodynamics in the ER, $\mathrm{LH}$, and TER processes. The change in the Gibbs free energy is:

$$
\Delta \mathrm{G}=\Delta \mathrm{E}+\Delta \mathrm{E}_{\mathrm{ZPE}}-\mathrm{T} \Delta \mathrm{S}
$$

In the above formula, $\Delta \mathrm{G}$ is the difference between two successive steps of the reaction mechanism. $\triangle \mathrm{E}$ is the difference in total energy directly obtained from DFT calculations at $0 \mathrm{~K}$ and $\triangle \mathrm{EZPE}$ is energy in zero-point vibrational energy. $T$ is the temperature. $\Delta S$ is the entropy change and is defined by $\Delta S$ $=\Delta \mathrm{S}_{\mathrm{vib}}+\Delta \mathrm{S}_{\text {rot }}+\Delta \mathrm{S}_{\text {trans, }}$, where $\Delta \mathrm{S}_{\mathrm{vib}}, \Delta \mathrm{S}_{\text {rot }}, \Delta \mathrm{S}_{\text {trans }}$ are the contributions of vibrational, rotational, and translational modes, respectively.

For all three processes, $\Delta \mathrm{G}$ was changing very slightly. For the ER process, the barrier for IS1 $\rightarrow$ TS1 was $0.05 \mathrm{eV}$, for MS1 $\rightarrow$ TS2 was $0.04 \mathrm{eV}$. The barrier for IS2 $\rightarrow$ TS3 was $0.01 \mathrm{eV}$ (all at $298 \mathrm{~K}$ ). For the $\mathrm{LH}$ process, the barrier was $0 \mathrm{eV}$ for IS $\rightarrow \mathrm{TS} 1$, and $0.01 \mathrm{eV}$ for MS $\rightarrow \mathrm{TS} 2$. The barrier in the TER process was $0.02 \mathrm{eV}$ for IS $\rightarrow \mathrm{TS} 1$, and $0 \mathrm{eV}$ for MS $\rightarrow \mathrm{TS} 2$ (all at $298 \mathrm{~K}$ ). These values were small, and did not change much as the temperature was raised to $500 \mathrm{~K}$.

We could make a rough order of magnitude estimate of the rates of the reaction using the Arrhenius relationship. The reaction time for each step is roughly:

$$
\tau=\frac{1}{v e^{\left(\frac{-E a}{\kappa_{B} T}\right)}}
$$

where $E_{a}$ is the activation energy of the reaction, $\kappa_{B}$ is Boltzmann's constant $\left(8.617 \times 10^{-5} \mathrm{eV} / \mathrm{K}\right)$, and $v$ is the attempt frequency, which is estimated to be on the order of $10^{12} \mathrm{~Hz}$. At three representative temperatures $(298,400,500 \mathrm{~K})$, the estimated reaction times are shown at Table 2. For the ER process, the reaction time of each elementary step was estimated to be $\tau=2 \times 10^{3}, 6 \times 10^{8}$, and $2 \times 10^{-11} \mathrm{~s}$. For the LH process, IS1 $\rightarrow$ MS1, MS1 $\rightarrow$ FS1, and IS2 $\rightarrow$ FS2 had times $\tau=3 \times 10^{-11}, 3 \times 10^{-5}$, and $2 \times 10^{-11}$ s. For the TER process, the reaction times were $9 \times 10^{-5}$ and $4 \times 10^{-7}$ s, respectively (the TER analysis should also include the reactant concentrations for a more accurate estimate).

\begin{tabular}{|c|c|c|c|c|c|c|c|c|}
\hline \multirow{3}{*}{ Reaction Time } & \multicolumn{8}{|c|}{ Step } \\
\hline & \multicolumn{3}{|c|}{ ER } & \multicolumn{3}{|c|}{ LH } & \multicolumn{2}{|c|}{ TER } \\
\hline & IS1-MS1 & MS1-FS1 & IS2-FS2 & IS1-MS1 & MS1-FS1 & IS2-FS2 & IS1-MS1 & MS1-FS1 \\
\hline$\tau(\mathrm{s})$ at $298 \mathrm{~K}$ & $2 \times 10^{3}$ & $6 \times 10^{8}$ & $2 \times 10^{-11}$ & $3 \times 10^{-11}$ & $2 \times 10^{-5}$ & $2 \times 10^{-11}$ & $9 \times 10^{-5}$ & $4 \times 10^{-7}$ \\
\hline$\tau(\mathrm{s})$ at $400 \mathrm{~K}$ & 0.2 & $3 \times 10^{3}$ & $1 \times 10^{-11}$ & $1 \times 10^{-11}$ & $4 \times 10^{-7}$ & $1 \times 10^{-11}$ & $8 \times 10^{-7}$ & $1 \times 10^{-8}$ \\
\hline$\tau(\mathrm{s})$ at $500 \mathrm{~K}$ & 0 & 2.5 & $6 \times 10^{-12}$ & $8 \times 10^{-12}$ & $3 \times 10^{-8}$ & $6 \times 10^{-12}$ & $5 \times 10^{-8}$ & $2 \times 10^{-9}$ \\
\hline
\end{tabular}

Table 2. Estimated reaction times for steps in the ER, LH, and TER processes at 298, 400, and $500 \mathrm{~K}$. 
From the Arrhenius analysis, we concluded that the Ni SAC could operate at relatively low temperatures in the LH and TER processes. For the LH process, MS1 $\rightarrow \mathrm{FS} 1$ was the rate determining step. For the TER process, IS1 $\rightarrow$ MS1 was the rate determining step. All reactions became faster as the temperature was increased.

\section{Computational Methods}

We used the same general computational methods as in our previous work [26]. This method was shown to be satisfactory for these calculations in our previous work. We used the $\mathrm{Dmol}^{3}$ program in Materials Studio 2016 [37]. Spin-polarized DFT-D calculations were carried out using the $\mathrm{Dmol}^{3}$ package [37], which is part of Materials Studio 2016 (Accelrys, San Diego, CA, USA). The generalized gradient approximation using the PBE functional [38] with long-range dispersion correction via the Tkatchenko-Scheffler scheme [39] was used. We employed the DFT semi-core pseudopotentials (DSPP) [37], which replaces core electrons by a single effective potential to describe the core-valence interactions with some relativistic corrections. We used the double numerical plus polarization (DNP) basis set with a "fine" orbital cutoff. During the geometrical optimization, the convergence tolerances were set to $10^{-5} \mathrm{Ha}$ for the energy, $0.002 \mathrm{Ha} / \AA$ for the force, and $0.005 \AA$ for the displacement. The electronic self consistent field tolerance was set to $10^{-6} \mathrm{Ha}$. We estimated the total error in the binding energies and energy barriers to be $0.1 \mathrm{eV}$ [26]. A Fermi smearing parameter of $0.003 \mathrm{Ha}$ was used in the calculations to achieve quick and accurate electronic convergences.

The reciprocal space was sampled with a $(4 \times 4 \times 1)$ k-point grid generated automatically using the Monkhorst-Pack method for the relaxation calculations. Complete linear synchronous transit (LST)/quadratic synchronous transit (QST) calculations were performed to locate the transition states (TS). Moreover, the transition states were confirmed with frequency calculations by the number of imaginary frequencies (NIMG) with NIMG $=1$.

The calculated lattice constant of h-BN was $2.51 \AA$ with a B-N bond length of $1.45 \AA$. This was consistent with a previous work [31]. A $6 \times 6 \times 1$ supercell of h-BN containing 72 atoms was used as a support. A single transition metal atom substituted a B or $\mathrm{N}$ atom. DMol3 was set to auto to find the correct spin state in the unrestricted calculations. The thickness of the vacuum layer was more than $15 \AA$ to avoid interlayer interactions. The adsorption energy $\left(E_{a d s}\right)$ was determined using:

$$
E_{\text {ads }}=\left(E_{\text {adsorbate }}+E_{\text {support }}\right)-E_{\text {adsorbate/support }}
$$

$E_{\text {adsorbate }}, E_{\text {support }}$, and $E_{\text {adsorbate/support }}$ are the total energies of the free adsorbate, the support, and the support with the adsorbate. All three energies were derived from calculations using the same periodic dimensions and the same computational settings. A positive value indicates an exothermic adsorption.

\section{Conclusions}

In this work, we studied h-BN nanosheets with individual TM metal ( $\mathrm{Sc}, \mathrm{Ti}, \mathrm{V}, \mathrm{Cr}, \mathrm{Mn}$ and Ni) catalytic sites located at defects using DFT-D calculations. After studying the adsorption of reactants and products, we decided to focus on Sc, $\mathrm{Cr}$, and Ni. We considered the detailed processes of $\mathrm{CO}$ catalytic oxidation to $\mathrm{CO}_{2}$ on $\mathrm{Ni}$. The ER, $\mathrm{LH}$, and the new TER processes were evaluated. Sc did not readily catalyze $\mathrm{CO}$ oxidation. $\mathrm{Cr}$ catalyzed $\mathrm{CO}$ oxidation with the ER process, although the $\mathrm{CO}+\mathrm{O}$ $(\mathrm{ad}) \rightarrow \mathrm{CO}_{2}$ (gas) step has a large $1.3 \mathrm{eV}$ barrier. For the Ni catalyst, the MS1 to TS2 step dominated the formation of $\mathrm{CO}_{2}$ in the ER process (1.2 eV barrier). For the $\mathrm{Ni} \mathrm{LH}$ process, the $\mathrm{OOCO}(\mathrm{ad}) \rightarrow \mathrm{CO}_{2}(\mathrm{gas})+$ $\mathrm{O}(\mathrm{ad})$ step determined the reaction rate with a low $0.44 \mathrm{eV}$ barrier. For the Ni TER process, the activation of $\mathrm{O}_{2}$ to the OCO-Ni-OCO intermediate was the rate determining step with a low $0.47 \mathrm{eV}$ barrier. We concluded that the proposed Ni-BN materials should be stable and active catalysts between 300 and $500 \mathrm{~K}$. 
Author Contributions: Conceptualization, L.-M.Y.; Investigation, Y.L. and L.-M.Y.; Project administration, L.-M.Y. and E.G.; Computational Resources, E.G.; Supervision, L.-M.Y.; Writing original draft, Y.L. and L.-M.Y.; Writing-review \& editing, E.G.

Funding: Y.L. and L.-M.Y. gratefully acknowledge support from the National Natural Science Foundation of China (21673087 and 21873032), Startup Fund (2006013118 and 3004013105) from Huazhong University of Science and Technology, and the Fundamental Research Funds for the Central Universities (2019kfyRCPY116).

Acknowledgments: We thank the Minnesota Supercomputing Institute (MSI) at the University of Minnesota for supercomputing resources.

Conflicts of Interest: The authors declare no conflict of interest.

\section{References}

1. Kummer, J.T. Catalysts for automobile emission control. Prog. Energy Combust. Sci. 1980, 6, 177-199. [CrossRef]

2. Freund, H.J.; Meijer, G.; Scheffler, M.; Schlögl, R.; Wolf, M. CO oxidation as a prototypical reaction for heterogeneous processes. Angew. Chem. Int. Ed. Engl. 2011, 50, 10064-10094. [CrossRef] [PubMed]

3. Bleakley, K.; Hu, P. A density functional theory study of the interaction between $\mathrm{CO}$ and O on a Pt Surface: $\mathrm{CO} / \mathrm{Pt}$ (111), O/Pt (111), and CO/O/Pt (111). J. Am. Chem. Soc. 1999, 121, 7644-7652. [CrossRef]

4. Heiz, U.; Sanchez, A.; Abbet, S.; Schneider, W.-D. Catalytic oxidation of carbon monoxide on monodispersed platinum clusters: Each atom counts. J. Am. Chem. Soc. 1999, 121, 3214-3217. [CrossRef]

5. Allian, A.D.; Takanabe, K.; Fujdala, K.L.; Hao, X.; Truex, T.J.; Cai, J.; Buda, C.; Neurock, M.; Iglesia, E. Chemisorption of $\mathrm{CO}$ and mechanism of $\mathrm{CO}$ oxidation on supported platinum nanoclusters. J. Am. Chem. Soc. 2011, 133, 4498-4517. [CrossRef] [PubMed]

6. Bunluesin, T.; Cordatos, H.; Gorte, R. Study of CO oxidation kinetics on Rh/ceria. J. Catal. 1995, 157, $222-226$. [CrossRef]

7. Chen, M.S.; Cai, Y.; Yan, Z.F.; Gath, K.; Axnanda, S.; Goodman, D.W. Highly active surfaces for CO oxidation on Rh, Pd, and Pt. Surf. Sci. 2007, 601, 5326-5331. [CrossRef]

8. Eichler, A. CO oxidation on transition metal surfaces: Reaction rates from first principles. Surf. Sci. 2002, 498, 314-320. [CrossRef]

9. Liu, Z.-P.; Hu, P.; Alavi, A. Catalytic role of gold in gold-based catalysts: A density functional theory study on the CO oxidation on gold. J. Am. Chem. Soc. 2002, 124, 14770-14779. [CrossRef]

10. Lopez, N.; Nørskov, J.K. Catalytic CO oxidation by a gold nanoparticle: A density functional study. J. Am. Chem. Soc. 2002, 124, 11262-11263. [CrossRef]

11. Lopez, N. On the origin of the catalytic activity of gold nanoparticles for low-temperature CO oxidation. J. Catal. 2004, 223, 232-235. [CrossRef]

12. Thomas, J.M.; Raja, R.; Lewis, D.W. Single-site heterogeneous catalysts. Angew. Chem. Int. Ed. Engl. 2005, 44, 6456-6482. [CrossRef] [PubMed]

13. Qiao, B.; Wang, A.; Yang, X.; Allard, L.F.; Jiang, Z.; Cui, Y.; Liu, J.; Zhang, T. Single-atom catalysis of CO oxidation using Pt1/FeOx. Nat. Chem. 2011, 3, 634-641. [CrossRef] [PubMed]

14. Sun, S.; Zhang, G.; Gauquelin, N.; Chen, N.; Zhou, J.; Yang, S.; Chen, W.; Meng, X.; Geng, D.; Banis, M.N.; et al. Single-atom Catalysis Using Pt/Graphene Achieved through Atomic Layer Deposition. Sci. Rep. 2013, 3, 1775. [CrossRef]

15. Zhang, X.; Guo, J.; Guan, P.; Liu, C.; Huang, H.; Xue, F.; Dong, X.; Pennycook, S.J.; Chisholm, M.F. Catalytically active single-atom niobium in graphitic layers. Nat. Commun. 2013, 4, 1924. [CrossRef] [PubMed]

16. Lin, S.; Ye, X.; Johnson, R.S.; Guo, H. First-Principles Investigations of Metal (Cu, Ag, Au, Pt, Rh, Pd, Fe, Co, and Ir) Doped Hexagonal Boron Nitride Nanosheets: Stability and Catalysis of CO Oxidation. J. Phys. Chem. C 2013, 117, 17319-17326. [CrossRef]

17. Liu, X.; Duan, T.; Sui, Y.; Meng, C.; Han, Y. Copper atoms embedded in hexagonal boron nitride as potential catalysts for CO oxidation: A first-principles investigation. RSC Adv. 2014, 4, 38750-38760. [CrossRef]

18. Xu, G.; Wang, R.; Yang, F.; Ma, D. CO oxidation on single Pd atom embedded defect-graphene via a new termolecular Eley-Rideal mechanism. Carbon 2017, 118, 35-42. [CrossRef] 
19. Jiang, Q.G.; Ao, Z.M.; Li, S.; Wen, Z. Density functional theory calculations on the CO catalytic oxidation on Al-embedded graphene. RSC Adv. 2014, 4, 20290-20296. [CrossRef]

20. Li, Y.; Zhou, Z.; Yu, G.; Chen, W.; Chen, Z. CO catalytic oxidation on iron-embedded graphene: Computational quest for low-cost nanocatalysts. J. Phys. Chem. C 2010, 114, 6250-6254. [CrossRef]

21. Wu, P.; Du, P.; Zhang, H.; Cai, C. Graphyne-supported single Fe atom catalysts for CO oxidation. Phys. Chem. Phys. 2015, 17, 1441-1449. [CrossRef] [PubMed]

22. Ma, D.W.; Li, T.; Wang, Q.; Yang, G.; He, C.; Ma, B.; Lu, Z. Graphyne as a promising substrate for the noble-metal single-atom catalysts. Carbon 2015, 95, 756-765. [CrossRef]

23. Du, C.; Lin, H.; Lin, B.; Ma, Z.; Hou, T.; Tang, J.; Li, Y. MoS 2 supported single platinum atoms and their superior catalytic activity for CO oxidation: A density functional theory study. J. Mater. Chem. A 2015, 3, 23113-23119. [CrossRef]

24. Deng, D.; Chen, X.; Yu, L.; Wu, X.; Liu, Q.; Liu, Y.; Yang, H.; Tian, H.; Hu, Y.; Du, P.; et al. A single iron site confined in a graphene matrix for the catalytic oxidation of benzene at room temperature. Sci. Adv. 2015, 1, 1500462. [CrossRef] [PubMed]

25. Fei, H.; Dong, J.; Arellano-Jiménez, M.J.; Ye, G.; Kim, N.D.; Samuel, E.L.G.; Peng, Z.; Zhu, Z.; Qin, F.; Bao, J.; et al. Atomic cobalt on nitrogen-doped graphene for hydrogen generation. Nat. Commun. 2015, 6, 8668. [CrossRef] [PubMed]

26. Xu, L.; Yang, L.M.; Ganz, E. Mn-graphene single-atom catalyst evaluated for CO oxidation by computational screening. Theor. Chem. Acc. 2018, 137, 98. [CrossRef]

27. Jin, C.; Lin, F.; Suenaga, K.; Iijima, S. Fabrication of a freestanding boron nitride single layer and its defect assignments. Phys. Rev. Lett. 2009, 102, 195505. [CrossRef] [PubMed]

28. Alem, N.; Erni, R.; Kisielowski, C.; Rossell, M.D.; Hartel, P.; Jiang, B.; Gannett, W.; Zettl, A. Vacancy growth and migration dynamics in atomically thin hexagonal boron nitride under electron beam irradiation. Phys. Status Solidi-RRL 2011, 5, 295-297. [CrossRef]

29. Liu, X.; Duan, T.; Mang, C.; Han, Y. Pt atoms stabilized on hexagonal boron nitride as efficient single-atom catalysts for CO oxidation: A first-principles investigation. RSC Adv. 2015, 5, 10452-10459. [CrossRef]

30. Mao, K.; Li, L.; Zhang, W.; Pei, Y.; Zeng, X.C.; Wu, X.; Yang, J. A theoretical study of single-atom catalysis of $\mathrm{CO}$ oxidation using Au embedded two-dimensional h-BN monolayer: A CO-promoted $\mathrm{O}(2)$ activation. Sci. Rep. 2014, 4, 5441. [CrossRef] [PubMed]

31. Zhao, P.; Su, Y.; Zhang, Y.; Li, S.-J. CO catalytic oxidation on iron-embedded hexagonal boron nitride sheet. Chem. Phys. Lett. 2011, 515, 159-162. [CrossRef]

32. Lu, Z.; Lv, P.; Liang, Y.; Ma, D.; Zhang, Y.; Zhang, W.; Yang, X.; Yang, Z. CO oxidation catalyzed by the single Co atom embedded hexagonal boron nitride nanosheet: A DFT-D study. Phys. Chem. Phys. 2016, 18, 21865-21870. [CrossRef] [PubMed]

33. Lu, Z.; Lv, P.; Yang, Z.; Li, S.; Ma, D.; Wu, R. A promising single atom catalyst for CO oxidation: Ag on boron vacancies of h-BN sheets. Phys. Chem. Phys. 2017, 19, 16795-16805. [CrossRef] [PubMed]

34. Du, A.; Chen, Y.; Zhu, Z.; Amal, R.; Lu, G.Q.; Smith, S.C. Dots versus antidots: Computational exploration of structure, magnetism, and half-metallicity in boron- nitride nanostructures. J. Am. Chem. Soc. 2009, 131, 17354-17359. [CrossRef] [PubMed]

35. Lu, Z.; Lv, P.; Xue, J.; Wang, H.; Wang, Y.; Huang, Y.; He, C.; Mac, D.; Yang, Z. Pd1/BN as a promising single atom catalyst of $\mathrm{CO}$ oxidation: A dispersion-corrected density functional theory study. RSC Adv. 2015, 5, 84381-84388. [CrossRef]

36. Huang, C.; Ye, X.; Chen, C.; Lin, S.; Xie, D. A computational investigation of CO oxidation on ruthenium-embedded hexagonal boron nitride nanosheet. Comput. Theor. Chem. 2013, 1011, 5-10. [CrossRef]

37. Delley, B. From molecules to solids with the DMol3 approach. J. Chem. Phys. 2000, 113, 7756-7764. [CrossRef]

38. Perdew, J.P.; Burke, K.; Ernzerhof, M. Generalized gradient approximation made simple. Phys. Rev. Lett. 1996, 77, 3865. [CrossRef]

39. Tkatchenko, A.; Scheffler, M. Accurate molecular van der Waals interactions from ground-state electron density and free-atom reference data. Phys. Rev. Lett. 2009, 102, 073005. [CrossRef]

(C) 2019 by the authors. Licensee MDPI, Basel, Switzerland. This article is an open access article distributed under the terms and conditions of the Creative Commons Attribution (CC BY) license (http://creativecommons.org/licenses/by/4.0/). 